\section{Blood vessels} on demand

Growing blood vessels for use in cardiovascular surgeries is a tricky business. Vessels can be created from a patient's own cells, but the process is costly and takes up to nine months. Now researchers have devised a method that can churn out tens of vessels per donor that could then be stored until needed.

Shannon Dahl at Humacyte in Durham, North Carolina, and her collaborators grew their vessels by introducing the cells into scaffolds made of polyglycolic acid. Once these vascular grafts had grown in a bioreactor, the team stripped them of cells, reducing the likelihood of the vessels eliciting an immune response in the recipient.

The resulting collagen-tube grafts had similar properties to normal human blood vessels. When tested in a small number of baboons and dogs, most of the grafts remained open over test periods ranging between one month and one year.

Sci. Transl. Med. 3, 68ra9 (2011)

For a longer story on this research, see go.nature. com/9gyzog

\section{PHYSIOLOGY}

\section{Nitrate ups cells' efficiency}

Leafy vegetables are chock-full of nitrate - a molecule that seems to boost the efficiency of energy-producing organelles called mitochondria in muscle cells.

Filip Larsen, Eddie

Weitzberg and their group at the Karolinska Institute in Stockholm gave 14 volunteers either doses of nitrate similar to those found in certain foods or a placebo. Mitochondria collected from the muscle cells of those who had been taking nitrate for three days made $19 \%$ more energy-dense ATP molecules per oxygen molecule consumed than did those on the placebo.

Mitochondria must maintain an electrochemical gradient across their inner membrane to produce ATP. Levels of a protein that saps these organelles' conductivity were reduced in people taking nitrate, suggesting that their muscle cells were producing energy more economically. Cell Metab. 13, 149-159 (2011)

\section{NANOTECHNOLOGY}

\section{Wired up by DNA strands}

In the quest for ever-smaller electronics, DNA could function as a molecular wire, say Jacqueline Barton and her group at the California Institute of Technology in Pasadena. They report that a 34-nanometre-long monolayer of double-stranded DNA can transport electrical charge.

The researchers measured the current of electrons flowing from a gold electrode, down the DNA layer to a probe at the other end. Charge transport required perfect matching between the DNA's base pairs, with just a single mismatch in 100 base pairs hampering electron flow.

This is among the farthest that a molecular wire has transported charge, the authors say. They add that DNA's intrinsic long-range order, flexibility and ease of synthesis make it an attractive molecule for nanoelectronics. Nature Chem. doi:10.1038/ nchem.982 (2011) \section{FLUID DYNAMICS \\ What killed the top kill?}

Attempts to 'top kill' last year's oil spill in the Gulf of Mexico by ramming mud down the well may have failed because of the unsuitable properties of the drilling mud used.

Using coloured water and mineral oil, Jonathan Katz of Washington University in St Louis, Missouri, and his colleagues show that the outrushing oil may have broken up the incoming column of mud into small

COMMUNITY CHOICE

The most viewed papers in science

PROTEOMICS

\title{
Toxic clumps trap many proteins
}

\section{HIGHLY READ \\ on www.cell.com in January 2010}

Neurodegenerative disorders such as Parkinson's disease are marked by the presence of toxic protein aggregates in brain cells. These aggregates seem to ensnare a range of proteins that share certain biochemical features and are involved in important cellular processes.

Martin Vabulas at the Max Planck Institute of Biochemistry in Martinsried, Germany, and his colleagues designed artificial $\beta$-sheet proteins that form clumps similar to the amyloid fibrils seen in several neurodegenerative diseases. They expressed the proteins in human cells and analysed the native proteins that bound to the aggregates. The researchers found that various proteins involved in RNA processing, protein production and other key functions were caught up in the aggregates: in a few cases, the entangled proportion was as high as $45 \%$. These proteins tended to be larger in size and have more unstructured regions than their non-sequestered counterparts. Moreover, the proteins interact with hundreds of other essential proteins. Cell 144, 67-78(2011)

droplets (pictured left, in green). They also show that future wells could be killed more easily by using material that becomes stiff when stretched rapidly — in this study, water with added corn starch (right). This would allow the mud to travel down the well as a slug — without getting churned up - and form a seal. Phys. Rev. Lett. 106, 058301 (2011)

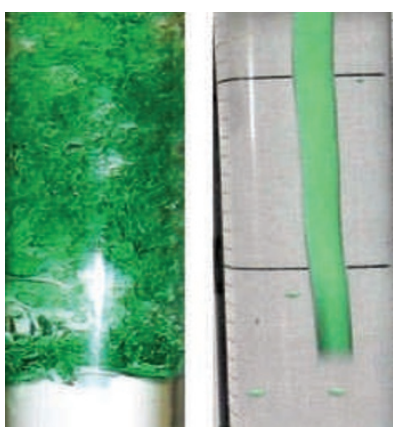
CANCER GENETICS

\section{Teasing apart cancer's influences}

Genetic mutations that arise after birth are one of cancer's main drivers. But what effect do inherited 'germline' genetic variants have on the progression of tumours with these mutations?

A team led by Allan Balmain at the University of California, San Francisco, studied how germline genetic variants affected the expression of genes associated with skin cancer in mice. The authors used animals genetically prone to developing cancerous tumours that had been treated with tumour-inducing chemicals. They say these mice are more relevant models for human genetic heterogeneity than other mouse strains typically used for cancer research.

The team found that the effect of germline variants on gene expression decreased as skin tumours progressed, indicating that the spontaneous mutations may have rewired genomic networks. However, this rewiring may also have led to the expression of certain genes linked to inflammation and tumour susceptibility coming under germline control in tumours.

Genome Biol. 12, R5 (2011)

\section{DNATURE.COM}

For the latest research published by Naturevisit:

www.nature,com/latestresearch 